\title{
The Business Process Reconstruction of Railway-River Combined Transportation Cloud Platform Taking China Container Export as an Example
}

\author{
Furong Jia $\mathbb{D}$, Lin Sun, Jiaxin Yuan, Yongping Li, and Qiang Huang \\ College of Information Engineering, Sichuan Agricultural University, Ya'an City, Sichuan 625014, China \\ Correspondence should be addressed to Qiang Huang; 19623556@qq.com
}

Received 4 April 2021; Revised 26 April 2021; Accepted 7 August 2021; Published 2 September 2021

Academic Editor: Chi-Hua Chen

Copyright (c) 2021 Furong Jia et al. This is an open access article distributed under the Creative Commons Attribution License, which permits unrestricted use, distribution, and reproduction in any medium, provided the original work is properly cited.

\begin{abstract}
In recent years, major large ports in China have realized the business informatization of rail-water intermodal transportation. However, the overall development level of intermodal transportation informatization has been restricted to a great extent due to the unbalanced development of intermodal transportation informatization in different regions, the rigid system architecture, the low degree of information sharing, and the lack of data management and analysis methods. Combined with the structure and business characteristics of intermodal transportation information systems, adopting cloud computing and Big Data technology, we propose an intermodal transportation information process with waybill as the information carrier and FPMS as the service fulcrum in this paper. Illustrated by the example of China's container export process, this paper explores a series of key technical issues in the cloud environment, such as application management, business information sharing, and Big Data processing, at different levels of the construction of the rail water transport cloud platform, combined with its business characteristics, and makes experimental analysis on the relevant models to verify the feasibility of the reconstruction of the rail water transport cloud platform. It can provide theoretical and practical support for the development of rail water intermodal informatization in China.
\end{abstract}

\section{Introduction}

At present, the information construction of railway-river transportation in China is all centered on ports, lacking overall planning, and there are many redundant constructions [1]. There are many differences in the information system construction architecture of various ports, which lead to serious information heterogeneity. At the same time, this information processing mode requires the railway to dock with different ports one by one, which will consume a lot of unnecessary time when the railway information is docked with the port business process, and the port also lacks effective expectation and control of the business growth [2]. With the continuous emergence of new combined transport services and the rapid expansion of the scale of services, the entropy value of the combined transport information system scattered in various ports will increase rapidly and cannot bear the burden of business development [3]. Che Kingsley chenikwi establishes the possibility of sustainable multimodal transportation by integrating different transportation methods to solve the problem of transportation fragility and promote the development of effective and efficient transportation networks in sub-Saharan Africa [4]. The loading and unloading operations of the Port of Rotterdam in the Netherlands are all managed and controlled by computers, and the development and construction of logistics parks are actively carried out to give full play to the logistics advantages of the port. The British railway transportation system actively cooperates with the port transportation system to comprehensively improve transportation quality and efficiency.

There are relatively rich theoretical studies on domestic and foreign ports and railway river transport and related issues, mainly for container ports, focusing on the improvement of railway river transport quality and efficiency, 
the optimization of railway river transport, and the integration and optimization of railway-rail transport models and algorithms. The railway-rail transportation standardization service system has been established, but there is little research experience on the railway river transportation information platform. This article focuses on verifying the feasibility of rebuilding the railway river transportation cloud platform, and provides theoretical and practical support for the development of the railway river.

The main work of this paper is summarized as follows:

(1) This paper proposes a cloud platform for railway inland transportation, which applies information technology to the "centralized" mode of informatization. Adopting the information management mode of "large concentration" can make full use of virtualization technology, give play to the advantage of resource intensification, and centralize the management of intermodal transportation information system and business data distributed in various ports. In the large centralized management mode, the powerful resource management ability of cloud platform can be effectively used, so that small- and medium-sized ports can get rid of the limitation of intermodal information, scientifically and reasonably manage and control the cost, properly deal with the management complexity and other problems, and have the same level of intermodal information as large ports in a short time. Compared with the decentralized information layout, the main advantages of the "large concentration" mode are shown in Table 1 [5].

(2) The integration and reconstruction of the overall business and the realization of hierarchical management of the process can effectively simplify the information interaction process, improve the efficiency of information integration, and more effectively manage the combined transportation information system and the business data distributed in each port [6].

(3) The business operation simulation process of Petri net model is established, which improves the business efficiency of MTR docking and reduces the cost. Container transportation process is characterized by dynamic, uncertainty, and complexity. Compared with the existing process modeling methods, such as event-driven process chain, data flow diagram, IDEF and Petri net, the Petri net can analyze the performance of the process concisely and efficiently. The comparison of methods is shown in Table 2 [7].

\section{The Information Layout of the Cloud Platform of Railway-River Combined Transport}

2.1. Intermodal Transportation Information Distribution Status. At present, China's railway-river transport informatization is constructed in a decentralized way centering on ports [8]. Each port builds its transport information system according to its business development, and integrates information with other transport participating institutions, as shown in Figure 1.

As shown in Figure 1, large ports have invested a lot of energy in planning their own business and building a relatively complete intermodal information system [9]. Small- and medium-sized ports are incomplete due to manpower and financial constraints. The railway-river transport information platform is a complex giant system. In addition to the characteristics of the general information system, it must be integrated, dynamic, and real-time. We found that the current disparate intermodal information layout and the isomerization of information systems are serious through the investigation of the intermodal information system of Lianyungang, Ningbo Port, and other ports. Problems such as resulting in a low level of informationization in China's intermodel transportation, low level of information sharing and interaction, and disproportion service capabilities [10].

\subsection{Advantages of "Centralized" Information Management} Mode. According to information layout problems of intermodal transportation at present, this paper argues that the railway-river intermodal cloud platform should be involved in the business of the construction of railways, ports, and other departments jointly. Using the centralized information management mode to construct the railway-river intermodal cloud platform can make better use of virtualization technology, give full play to the advantages of resource-intensive, and realize the centralization of distributed port transportation management information system and business data [11]. The main advantages of the "centralized" mode are as follows [12]:

(1) All port business processes are standardized and unified.

(2) It makes data mining easy because of unified data storage, real-time sharing of information between ports, and access is restricted by the permission system.

(3) The intermodal management agencies make one investment in the port, centralized operation, and maintenance, so the maintenance cost is low.

(4) Information is exchanged through cloud service mode, and service resources can be shared among tenants with a high utilization rate. Renting services on demand instead of buying software with low cost; unified service port, access can be anytime, anywhere, large service capacity, and high reliability.

(5) Flat operation and maintenance mode, highly shared operation and maintenance personnel, high utilization, and efficiency.

(6) Use unified service portal, join port more, and promotion efficiency is higher.

(7) Centralized risk control ensures service and network communication quality through high reliability of the cloud and adopts a unified application security strategy to ensure information security. 
TABle 1: Comparison of technical advantages between decentralized layout and centralized mode.

\begin{tabular}{|c|c|c|}
\hline Indicators/models & Distributed layout & Large concentration mode \\
\hline Business standardization & $\begin{array}{l}\text { Port business process is not unified and data } \\
\text { management is difficult }\end{array}$ & $\begin{array}{c}\text { All port business processes are standardized and } \\
\text { unified }\end{array}$ \\
\hline Information sharing & $\begin{array}{l}\text { It is difficult to realize information sharing among } \\
\text { ports, and the data are scattered in each port, so it is } \\
\text { difficult to extract and mine the data }\end{array}$ & $\begin{array}{l}\text { The data can be stored in a unified way, the } \\
\text { information between ports can be shared in real time, } \\
\text { the reading is limited by the permission system, and } \\
\text { the data mining is easy }\end{array}$ \\
\hline Construction cost & $\begin{array}{c}\text { Repeated investment and high maintenance cost of } \\
\text { port }\end{array}$ & $\begin{array}{c}\text { One-time investment and centralized operation and } \\
\text { maintenance by combined transport management } \\
\text { organizations }\end{array}$ \\
\hline $\begin{array}{l}\text { Application development } \\
\text { and update difficulty }\end{array}$ & $\begin{array}{r}\text { The "chimney" structure is } \\
\text { renewal cy }\end{array}$ & $\begin{array}{c}\text { Using the virtual software package, the system update } \\
\text { cycle is short }\end{array}$ \\
\hline $\begin{array}{l}\text { Information exchange } \\
\text { mode }\end{array}$ & $\begin{array}{l}\text { Information interaction based on system has low } \\
\text { resource utilization, high interaction cost, low } \\
\text { efficiency, and poor reliability }\end{array}$ & $\begin{array}{c}\text { Information is exchanged through cloud service mode, } \\
\text { and service resources can be shared among tenants } \\
\text { with high utilization rate; it is cheap to rent services on } \\
\text { demand instead of purchasing software; the service } \\
\text { port is unified and can be accessed anytime and } \\
\text { anywhere, with large service capacity and high } \\
\text { reliability }\end{array}$ \\
\hline $\begin{array}{l}\text { Operation and } \\
\text { maintenance mode }\end{array}$ & $\begin{array}{l}\text { Vertical operation and maintenance mode, serious } \\
\text { redundancy of operation and maintenance personnel, } \\
\text { low utilization and efficiency }\end{array}$ & $\begin{array}{l}\text { Flat operation and maintenance mode, highly shared } \\
\text { operation and maintenance personnel, high utilization } \\
\text { and efficiency }\end{array}$ \\
\hline
\end{tabular}

TABLE 2: Comparison of process modeling methods.

\begin{tabular}{lcccc}
\hline Attributes & Petri net & EPC & DFD & IDFE \\
\hline Dynamism & Strength & Strength & Weakness & Weakness \\
Description method & Graphical & Structured and graphical & Graphical & Structured \\
Process simulation & Supported & Unsupported & Supported & Unsupported \\
Modeling direction & Process oriented & Blend & Process oriented & Process oriented \\
Comprehensibility & Strength & Strength & Strength & Weakness \\
Expressive ability & Good & General & Good & General \\
\hline
\end{tabular}

2.3. Information Layout Mode of Intermodal Cloud Platform. Combining with the current informatization layout disadvantages of intermodal transportation, on the basis of making full use of the advantages of cloud platform intensive resource management, the centralized construction of software and hardware resources and the unified migration of applications are realized, forming a highly centralized information layout mode, as shown in Figure 2.

As shown from the information layout, management mode is based on the cloud platform which breaks the platform independence of each other between the pattern of using virtualization technology to restructure and computing resources to each according to its need. This mode will be dispersed in the ports intermodal business application migration to the cloud to intensive management and by the unified entrance of foreign service, to provide one-stop integrated transport business information service, at the same time also can use the cloud application service mode for users effectively and personalized business needs rapid customization resources or business environment. The cloud platform based on information centralization management mode can make full use of the cloud scale effectively due to numerous ports in China. And it can greatly reduce the information cost of the whole industry, especially for many small and medium-sized ports, which can through a variety of terminal direct access and use the cloud computing resources platform, achieving zero cost information construction investment [13].

\section{Business Process Restruction}

It is necessary to further extract the business information based on the transportation organization process, combine the cloud platform system oriented to the centralized transport information management, build the business support system, build the Big Data system combined with the Big Data processing mode, and take the centralized box import and export as an example to reconstruct the operation information process of railway-river combined transport.

3.1. Business Support System Architecture Design. The business support system mainly aims at six major user groups: cargo owners/through transport operators, railway, port, shipping companies, one customs clearance, two inspections and other government agencies, as well as container truck distribution companies/insurance banks to provide application information services [14]. The information demand relationship between these six major user groups and the business support system needs to optimize the following 


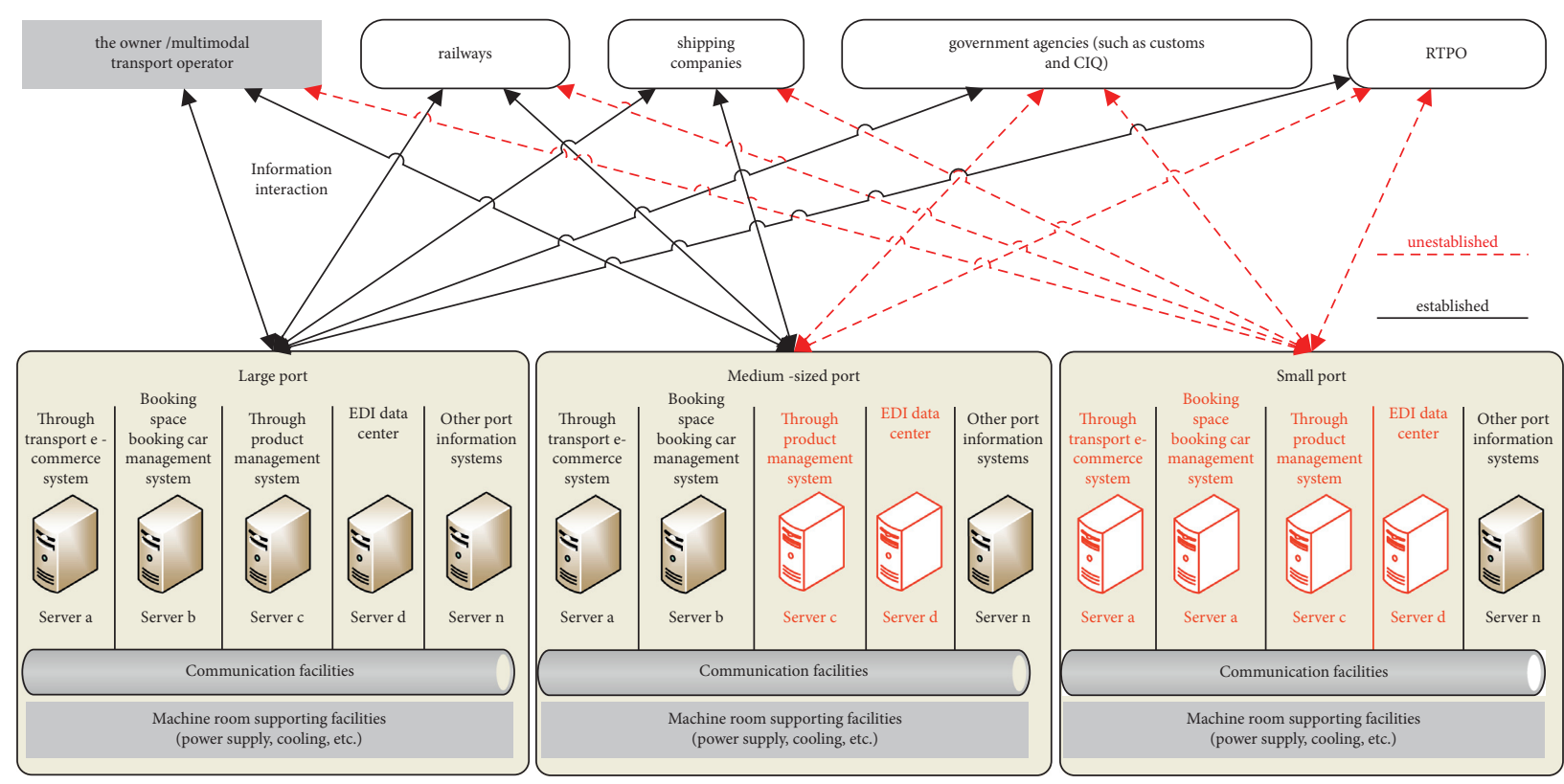

Figure 1: The port-centered information model of railway-river combined transport.

business on the basis of the existing through transport information system in terms of functional demand: the first is to build one-stop through transport services with customers as the center; the second is to enhance the sharing level of information on through transport between railways and waterways; and the third is to realize the management and analysis of Big Data on through transport.

The main function of the business support system is to integrate the current decentralized intermodal transport information system into an organic whole on the hot-water intermodal transport cloud platform. After configuring service instances and access rights according to customer needs, the system will be delivered to users in the SaaS service mode as shown in Figure 3.

According to Figure 3, the business support system mainly includes five parts: security framework, unified service portal, intermodal Big Data application, information sharing pool, and third-party application pool. The functions are as follows:

(1) Security framework: UGAC is an SaaS service mode based on cloud environment, which is responsible for unified access control of applications to eliminate the application security bucket effect in the business process.

(2) Unified service portal: The core of business support system is unified service portal, which is composed of intermodal e-commerce system and freight process management system to realize intermodal business.

(3) Intermodal Big Data application: The application of intermodal Big Data mainly includes the system instance pool related to intermodal business, in which the intermodal e-commerce platform provides customers with information query, consignment handling, cargo tracking, and other related information services in various transportation operations.
Intermodal business system is mainly responsible for the planning, implementation, and management of intermodal logistics process. Intermodal marketing management system is mainly responsible for the standard formulation of intermodal products and freight rates. The collaborative office system is mainly used to ensure the normal daily management of the intermodal transport management department.

(4) Information sharing pool: The information sharing pool is mainly responsible for heterogeneous application integration and information sharing. It is oriented to the needs of intermodal transport participants and realizes business collaboration and information interaction between different transport modes. It is used for data exchange with private cloud applications, such as railway, large ports, government agencies, and other third-party applications.

(5) The third-party application pool: The third-party application pool is mainly composed of the business systems of the joint transport participating institutions, mainly including the business systems related to the joint transport of the port and railway departments, the small ports with low degree of information, and the fast provision of complete management information services related to the port station, wharf, and yard by means of leasing, so as to achieve zero information investment.

3.2. Technical Framework of Data Support System. Data support system is mainly used to realize the management and secondary utilization of Big Data in combined transport. To ensure the flexibility and expansibility of data management, data management and application are independent. The data support system first precipitates and sorts out and 


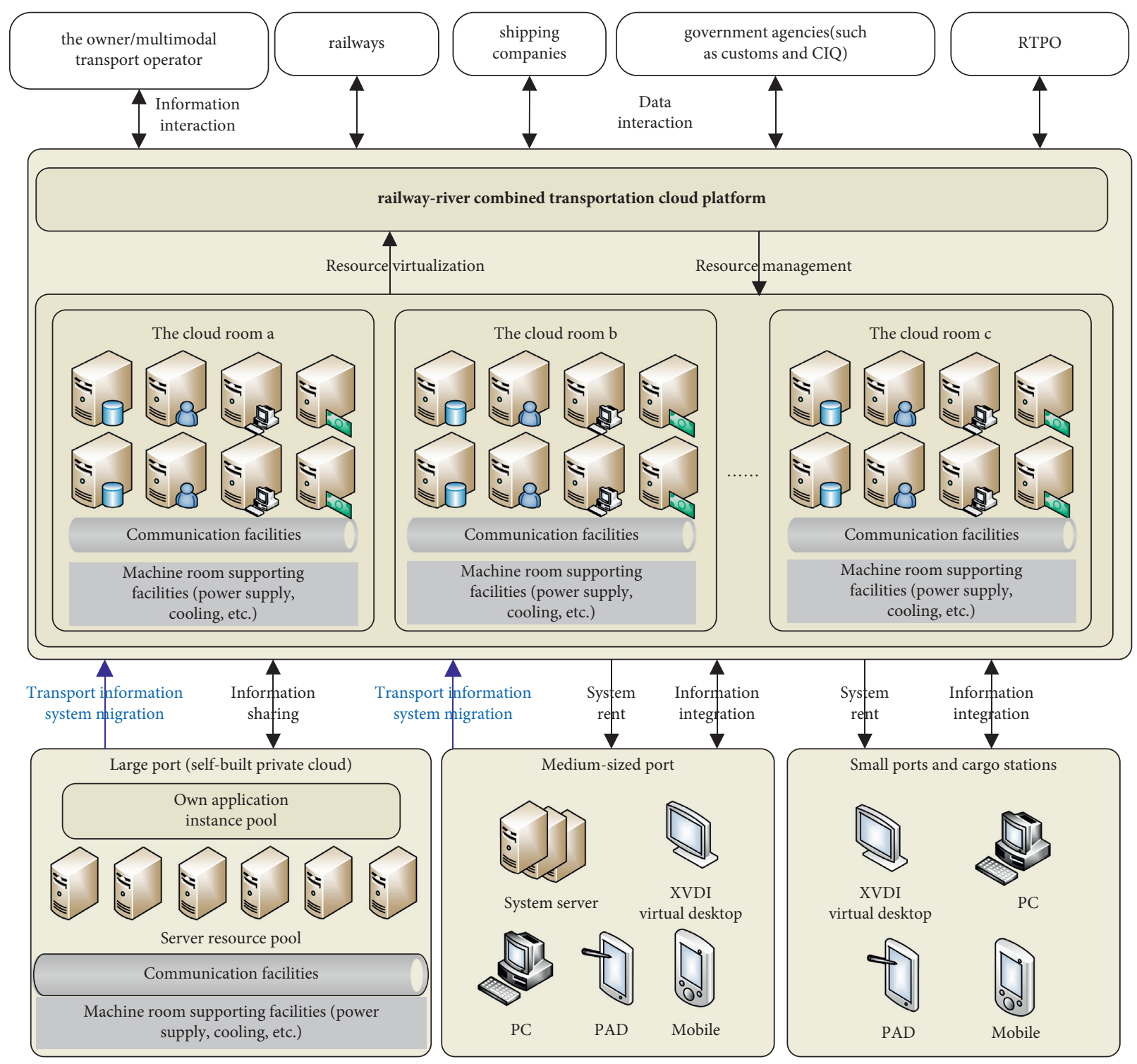

FIGURE 2: The centralized informatization mode of railway water cloud platform.

stores all through transport business data so as to form a data resource pool of the fragmented business data, then mines the precipitated data through the application of Big Data of through transport and delivers the results to the application of the business support system in the mode of data and service (DaaS) for consumption. These Big Data applications can, on one hand, react to the intermodal transportation applications that generate data and optimize the business itself; on the other hand, they can enhance the user experience and quality of service and provide valuable valueadded data services to the intermodal transportation participants and managers in other industries, thus enhancing the core value of the entire platform.

According to the design of cloud platform, the data support system based on DOA can not only retrieve and process Big Data efficiently but also decouple data management and application requirements, and provide flexible data services for users and managers of cloud platform. The technical framework design is shown in Figure 4.

As shown in Figure 4, the data support system is composed of client and cloud service side. The client side realizes the data interaction between the user and the data support system through protocol adapter, and the system interaction between the customer and the data support system is realized through the business application pool. The cloud service side mainly includes three components: the DOA data management center, the business application pool, and the Big Data analysis center, respectively, corresponding to the registration management, generation, and analysis process of the Big Data for intermodal transport. The functions are as follows:

(1) DOA Data Management Center: It is composed of a data storage terminal and a data registration center, in 


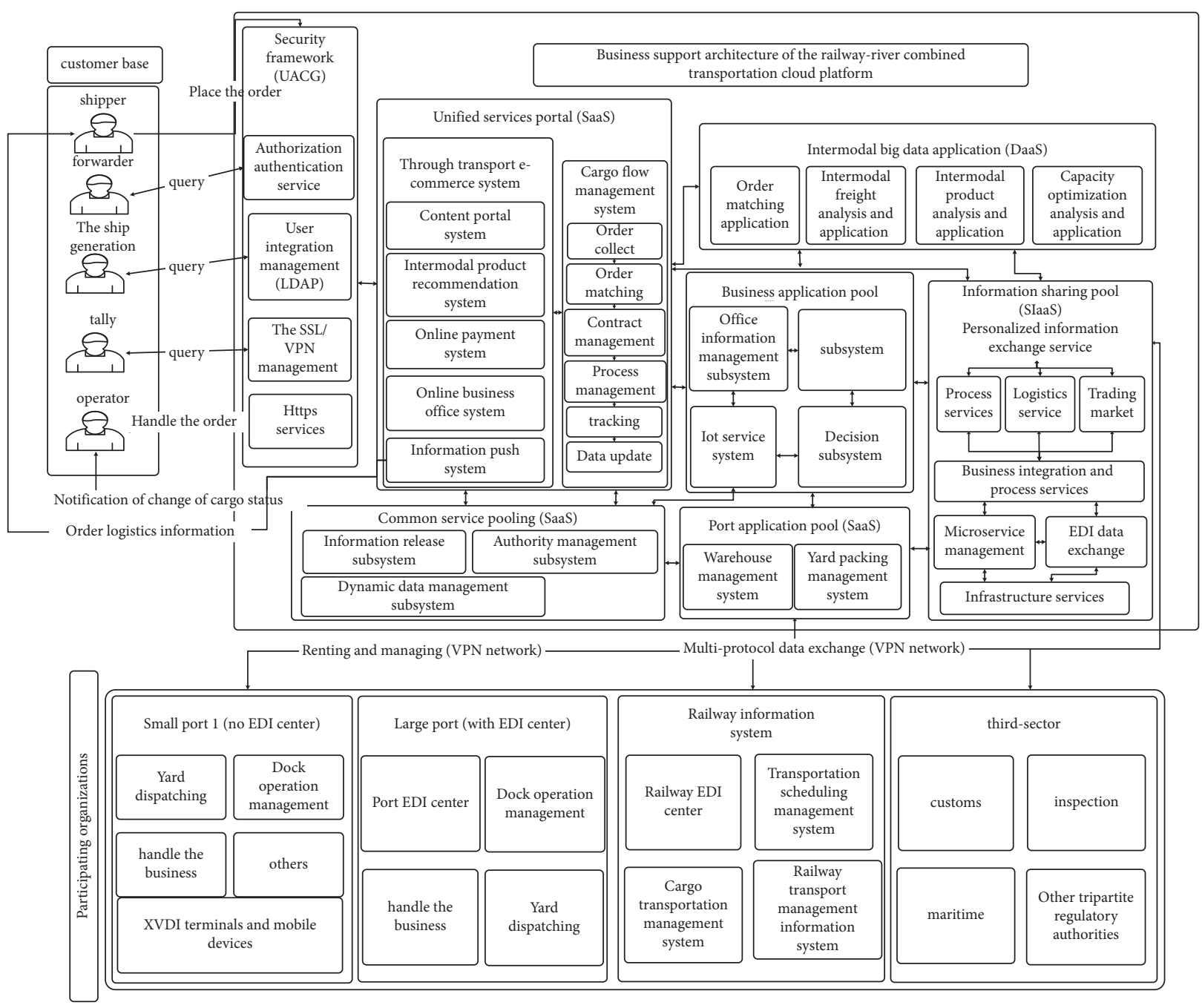

FIgURE 3: Business support architecture.

which the data storage terminal adopts an industrial cloud-distributed storage system to realize the unified storage and management of application data; the data registration center carries out unified management and operation of the data stored by the client and the service terminal through data registration, dynamic data aggregation of the client, and other technologies. The data are generated as needed in the metadata documents in the DOA Central Administration and stored in the metadata database in the registry. When a Big Data application needs to load a large amount of heterogeneous data for analysis, the DOA Central Administration retrieves the metadata information needed to load the data upon request and returns it to the Big Data application. A Big Data application system shall analyze the location and access interface of the data source from the metadata and obtain relevant data services. The data analysis results of Big Data applications are also stored in the data management center to form the corresponding data services (DaaS) for use by users and multimodal transport business applications. DOA data management center uses Spark protocol to realize the offline and online processing of combined transport data, and uses Hive data warehouse to manage the data information in distributed system. The better performance of Spark solves the problem of complicated data information in the course of operation and development of combined transport industry, and improves the efficiency of data processing. Hive-SQL realizes the transformation of MapReduce program, and improves the efficiency of data extraction and data cleaning. The performance comparisons of Spark with other data analysis platforms are shown in Table 3, and the characteristics of Hive are shown in Table 4.

(2) Business application pool: The business application pool can not only ensure the normal development of railway-water combined transport business but also be the producer of diversified combined transport Big Data from the perspective of data. These data are centrally stored and managed in the data support system, isolated by cloud service mode, and provided to combined transport Big Data applications as required. 


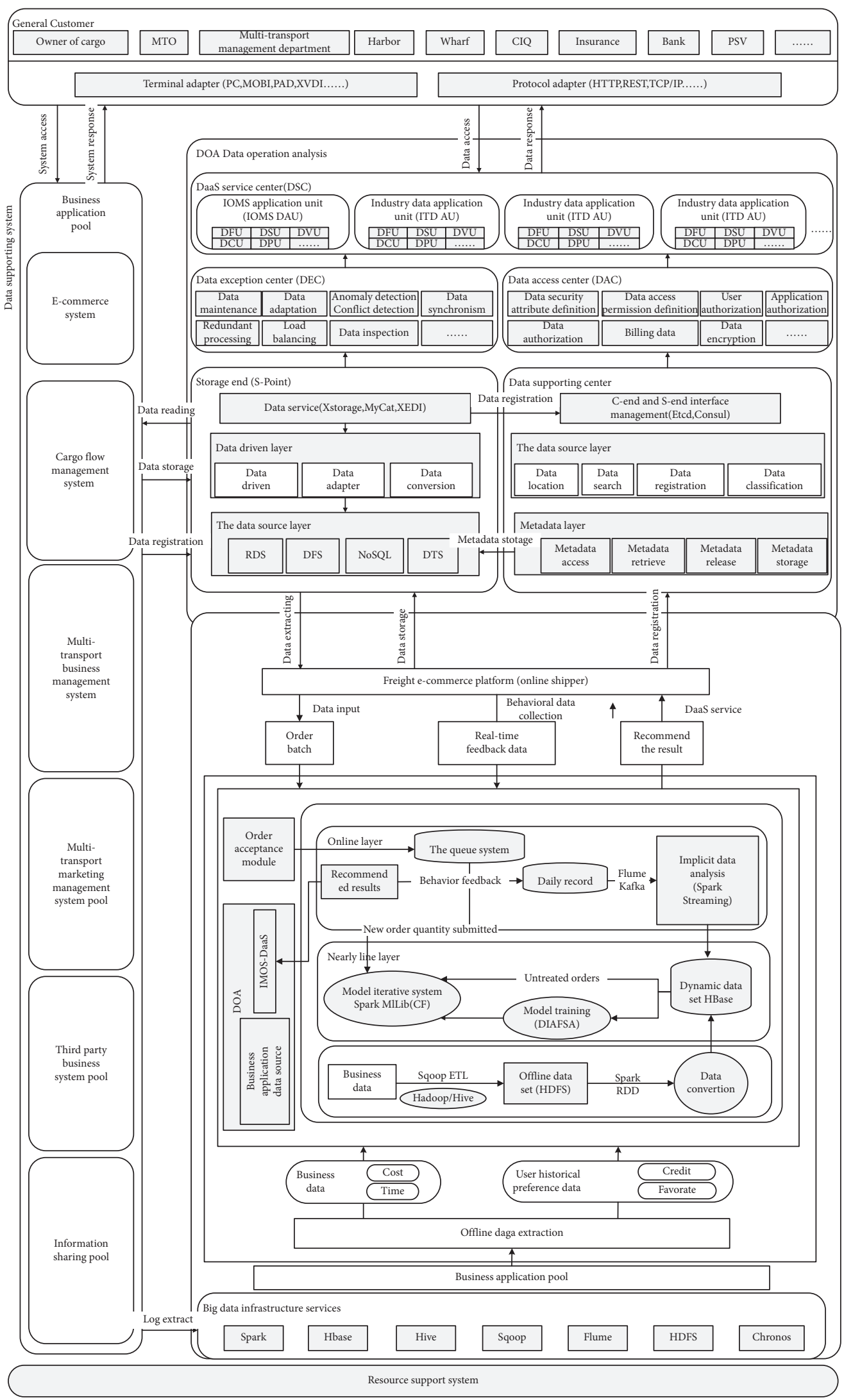

Figure 4: Data support architecture. 
(3) Big Data analysis center: The analysis center consists of a Big Data application pool, which is a collection of data processing units (ITDPUs) that are independent of each other and are designed and deployed according to application requirements, and a Big Data infrastructure service pool. ITDPU applies to DOA and extracts the data, then loads the data into ITDPU for data analysis, and finally returns the results to DOA administration center for business applications and industry users in the DaaS mode. The Big Data Infrastructure service includes seven parts: Spark, Hbase, Hive, Sqoop, Flume, HDFS, and Chronos, to serve the intermodal Big Data application pool. Spark realizes the offline and online processing of intermodal transport data, Hive realizes the cleaning of unstructured fragment data, HDFS realizes the storage of Big Data and becomes the offline data source of dynamic data set, Sqoop realizes the collection and processing of Big Data, Flume realizes the collection of user feedback data and log data, Hbase realizes the storage of dynamic data set, and Chronos regularly schedules the offline data transmission module and realizes the scheduling management of data processing system.

The three components of the data support system cooperate with each other to form a closed-loop ecosystem of Big Data from generation, storage, management, to extraction, analysis, feedback, and service. Therefore, in the data support system, DOA data management center, business application pool, and Big Data analysis center are indispensable.

3.3. Information Sharing Mechanism of Intermodal Transportation Cloud Platform. At present, the information sharing technologies adopted by ports, railways, and other core transport agencies mainly include the following:

(1) Electronic data interchange (EDI): EDI standardizes and formats the exchanged information according to the agreed protocol (EDIFACT, SOAP, etc.), and carries out data exchange among the computer network systems of trading partners through mail servers, FTP, Message Queue (MQ), and other data transmission systems, which can effectively solve the inefficient problem of paper information transmission $[15,16]$.

(2) Service oriented architecture (SOA): Its essence is enterprise application integration (EAI) technology that realizes information exchange between heterogeneous systems [17]. The SOA component model realizes the business information interaction between heterogeneous systems by defining standardized interfaces between different services, which is characterized by loose coupling, coarse granularity and transparency $[18,19]$.

(3) Enterprise service bus (ESB): The ESB takes services as the basic constituent unit and realizes service coordination among services through messages, and completes relevant business coordination [20]. The ESB can not only reduce development and maintenance effort, save costs, and improve system scalability but also better handle the heterogeneity between different technologies and protocols [21].

\section{Information Sharing Model Based on MSOA}

Microservice architecture (MSA) is a typical application architecture, which can be directly managed by the container cloud environment of resource support system, with strong flexibility and robustness. Using MSA to build the information sharing model and using microservice to replace the heavyweight bus structure of traditional SOA, information sharing components can be decentralized and more completely decoupled to improve the performance of message processing.

This paper proposes to take microservices as the carrier to virtualize and encapsulate the logic of the information sharing process, such as routing and message parsing. And combine them dynamically according to the information sharing needs to form a microservice oriented architecture (MSOA) information sharing model, which is the core of the information sharing pool of the business supporting system. This model can make full use of the advantages of the integrated application management system and make the information sharing function available to users in the cloud service mode of information Integration as a service (SIaaS), to realize the on-demand sharing of intermodal transportation information.

Different from the current bus sharing technology of information of combined iron-water transportation and intermodal transportation, the information sharing model based on MSOA uses fine-grained microservice unit to decouple information interaction, and uses container virtual image for standardization to form a lighter and more flexible decentralized structure than the traditional cloud platform based on the virtual machine. In addition, the MSOA Shared unit can be distributed and managed under the same management system. It avoids the high cost caused by the deployment of a special server required by the current information sharing technology and makes full use of its scaling mechanism to improve the concurrency performance of the information sharing system. All because it is fully compatible with the intermodal application structure.

4.1. Model Framework Design. The MSOA sharing model is built on the application pool managed by the resource support system, which encapsulates and combines the information sharing business with the microservice as the unit, calculates resource allocation on demand under the resource support system, and provides it to the freight flow management department. Finally, the SIaaS mode is adopted to uniformly deliver to service consumers for use. The intermodal transportation participating organizations and customers only need to rent relevant shared services according to business needs to realize information sharing. The architectural design is shown in Figure 5. 
TABle 3: Performance comparison between spark and other data analysis platforms.

\begin{tabular}{|c|c|c|c|}
\hline $\begin{array}{l}\text { Data analysis } \\
\text { platform }\end{array}$ & Hadoop & Spark & Storm \\
\hline $\begin{array}{l}\text { Data processing } \\
\text { model }\end{array}$ & Batch processing & Batch and real-time processing & Real-time processing \\
\hline Delayed & Higher & Second level & Real time \\
\hline Cluster support & Thousands of nodes & Over 1000 nodes & Good \\
\hline Throughput & Good & Good & Quite good \\
\hline Applicable scene & $\begin{array}{c}\text { Mass computation with low } \\
\text { timeliness }\end{array}$ & $\begin{array}{c}\text { Large data blocks need high-effective small-batch } \\
\text { computation }\end{array}$ & $\begin{array}{c}\text { Real-time analysis of small data } \\
\text { blocks }\end{array}$ \\
\hline
\end{tabular}

TABle 4: The characteristics of hive.

\begin{tabular}{lc}
\hline Characteristics & Hive \\
\hline $\begin{array}{l}\text { Scalability } \\
\text { Metadata management }\end{array}$ & Computational/scalability capabilities are designed for very large data sets \\
$\begin{array}{l}\text { Malleability } \\
\text { Fault tolerant }\end{array}$ & Provide unified metadata management \\
& Hive supports user-defined functions that users can implement according to their own needs \\
\hline
\end{tabular}

According to Figure 5, the MSOA architecture consists of the management core of the Intermodal Transportation Integration Unit (ITIU), which is divided into the management layer and the business layer, in which the management layer is mainly responsible for the interface registration and process management of the ITIU and consists of the following three systems:

(1) Microservice governance system. Microservice governance system is responsible by MSA and application registration center of resource support system, which provides registration management of shared interface of intermodal application and service composition of ITIU. MSA registry is based on application, without the concept of SOA bus, and only provides service query, load balancing and fault-tolerant mechanism. The direct communication between services does not need to rely on any service bus, which can effectively decentralize the information sharing model.

(2) EDI message switching system: Unlike the ESB, the protocol supported by the MSA is not perfect, and the RPC-based synchronous invocation approach cannot guarantee performance stability when invoked remotely across regions and is only suitable for information integration between homogeneous CNA applications; and for heterogeneous information integration across departments (for example, with ports and railways, and government departments), EDI is currently the most widely used data standard in the combined transport industry. In the MSOA model, EDI is no longer used as an information integration bus, but only as a message exchange module, which is only used to realize the interdepartmental and interregional information integration.

(3) Process management system: After the integration of MSOA application information, it needs to be combined according to the shipping business process used by freight process management system (FPMS). Process management mainly relies on workflow system to provide cross-application business process integration support, and choreographs the underlying application components and services after being integrated by MSA.

Therefore, for the MSOA transport information sharing model architecture, the management's microservice governance system, EDI message exchange system, process management system, and business layer are of great importance.

4.2. ITIU Design and Implementation. In the freight business process, the shipping business is the beginning, determine the order data, complete the forwarding. At this time, railway and waterway departments also need to carry out specific operations to implement specific transport events and procedures. The business process of consign apply integration unit (CAIU) is defined as follows:

(1) FPMS applies to the MSOA Shared model for shipping.

(2) The MSOA shared model invokes the CAIU service. It is independently based on the current capacity status, judges the result of the application, and sends it to the railway department, which will approve it.

(3) Finally, CAIU transmits the relevant results to FPMS (for customer inquiry) and the relevant waterway departments (to arrange relevant plans).

The cross-system interaction process of CAIU is shown in Figure 6.

As can be seen from Figure 6, CAIU consists of four roles and four interaction processes. From the perspective of workflow, the main process includes one judgment node and one concurrent node. CAIU's main four interactions are as follows: 


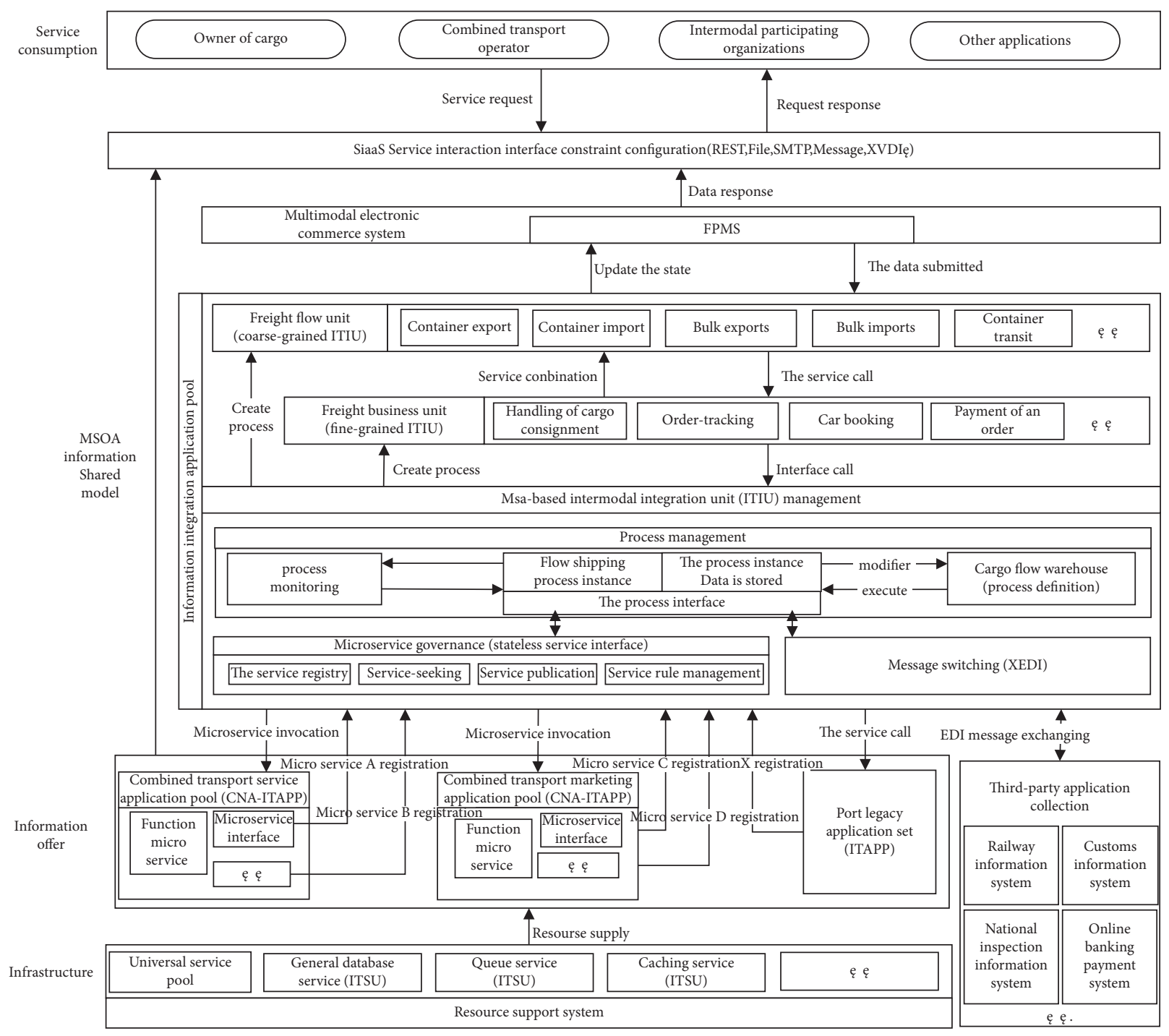

FIGURE 5: MSOA intermodal information sharing model framework.

(1) Order data submission interaction: FPMS submits to CAIU the basic cargo information, shipper information, consignee information, and shipping order information of the order.

(2) Vehicle application verification interaction: CAIU uses the intermodal freight management system to effectively compare the information of order goods and other data against the status of freight train capacity in the database, to judge whether the requirements for vehicle application are met or not.

(3) Order approval management interaction: based on the EDI system, CAIU transmits the verification result of vehicle application and the basic information message of order to the railway freight management department. With the assistance of the railway freight management information system, the railway management personnel carries out inspection, and there are no errors. Then CAIU replies the approval message of the application to CAIU.
(4) Order result interaction: CAIU sends the result of the order approval to FPMS and communicates with the shipper/intermodal operator for subsequent operations. If the consignment application is approved, send the order information to the freight station, make various plans in advance, communicate with the water transport department, and timely submit the relevant documents and approval results of the consignment.

4.3. Freight Flow Restruction Ideas. At present, the business process of combined transport is still faced with loads of problems, such as poor service quality, low concurrency, and lack of unified logistics information carrier. We established a unified business process model based on the transport cloud platform which can provide the whole information needed by users to improve business process efficiency [22].

The business process of combined transport is mainly comprised of an intermodal e-commerce system and the 


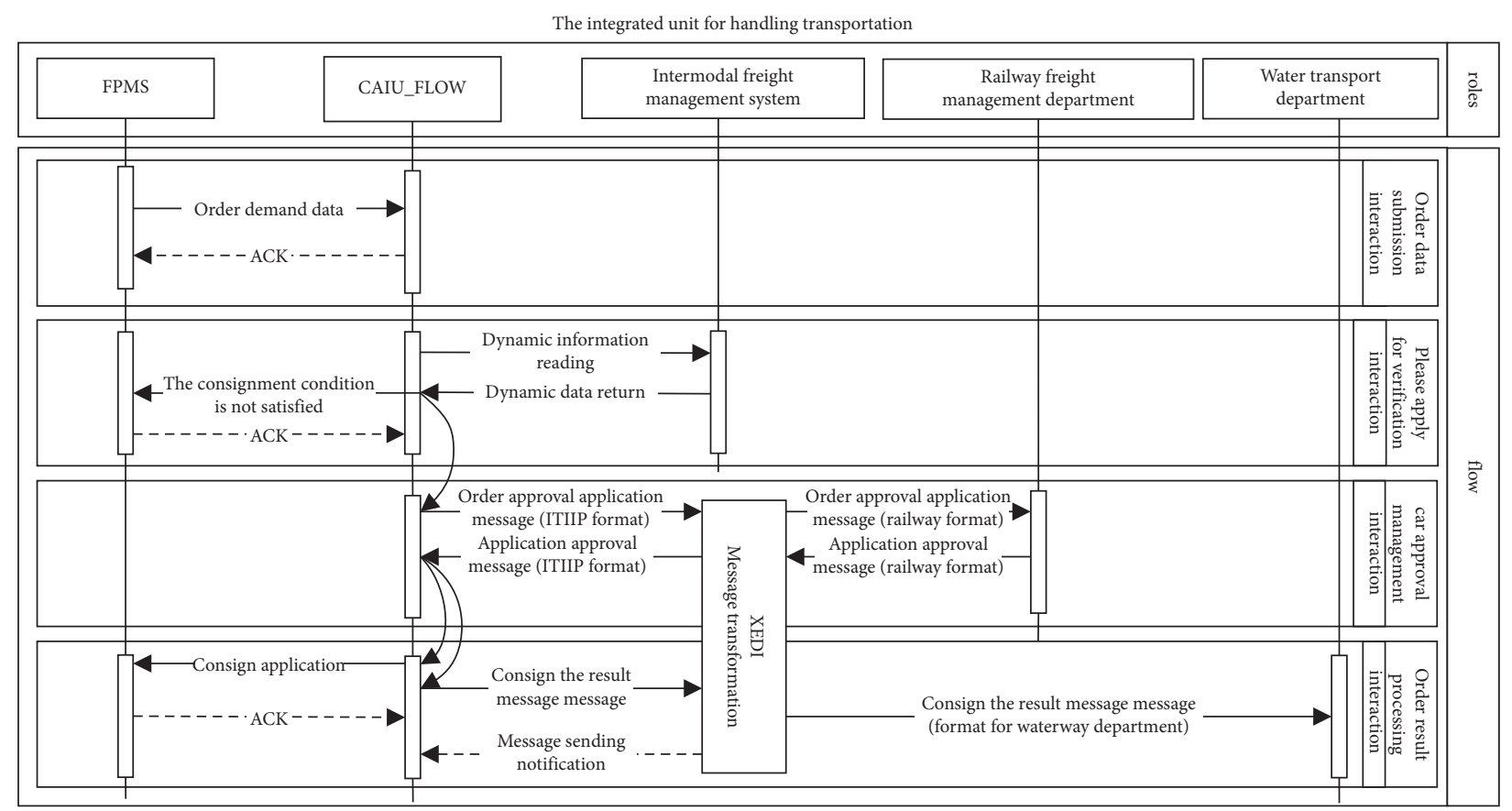

Figure 6: CAIU integrated unit design.

Freight Process Management System (FPMS). The former is an online $\mathrm{C} 2 \mathrm{C}$ freight business service platform provided by the intermodal transportation operator, who provides information service with the help of the participating institutions as a merchant. The shipper, as a buyer, applies for the business through a unified port online, including contracts management, orders tracking, and payment. FPMS adopts the order driven model (ODM) to manage the processes of combined transport logistics [23].

We propose a new intermodal transportation information process based on FPMS. They are handed over to FPMS for process management and information integration all after the consignment orders are collected by the e-commerce platform. From a macro perspective, the whole business process is divided into the following four stages:

(1) Order demand submission stage: after authentication and authorization, the shipper submits his/her consignment demand to the intermodal e-commerce platform. After collecting and collating the order, it transfers them to FPMS.

(2) Orders allocation: after obtaining the batch order from the e-commerce platform, FPMS automatically allocates them using the order-matching Big Data application. The system calculates the most optimal target operator and recommends it to the shipper. When the shipper confirms the targeted operator, it goes to the next stage.

(3) The business management of logistics: when the shipper finishes signing contracts, the intermodal transportation operator shall make the plan in accordance with the contract requirements. They will book a car and a ship, contact the customs or third parties online, and will feedback the item's status information through the interface to the e-commerce platform until the delivery is complete.

(4) Logistics management stage: after finishing online payment confirmation, service feedback, dispute arbitration, and service evaluation, and so on, it provides data support for subsequent decision analysis according to the completion status of the logistics business.

4.4. Information Flow Design of Centralized Box Outlet Based on FPMS. There is a bad difference between import and export business processes. Take the centralized container export process as an example. The design of the entire export process includes the freight business and freight transport process. It adopts FPMS intermediary guarantee transaction mode, which is divided into the following four steps mainly: (1) order submission; (2) order matching; (3) contract signing; and (4) payment confirmation.

The cargo transport process is roughly the same as the current process, which is mainly divided into the following nine links [24]: (1) shipment handling; (2) vehicle booking; (3) tally and loading; (4) railway transport; (5) transshipment of goods at the port; (6) customs inspection; (7) export preparation; (8) loading; and (9) delivery.

The traditional railway-river combined transport information process is complex and not unified. FPMS combines the business flow and logistics, and uses an electronic waybill, to realize the paperless cargo transport and online one-stop service. The combined transport information process based on FPMS mainly has the following advantages: 
(1) Business flexibility: FPMS can automatically recommend co-carriers for shippers to choose according to the order information of shippers.

(2) Business security: Shippers, intermodal operators, railways, ports, and so on, sign multiparty insurance, unified claims, and effectively reduce the risk of transport.

(3) Convenient transportation: The traditional railway and sea freight agents are integrated into the combined transport agent, and the shipper only needs to communicate with the combined transport agent, while the combined transport agent conducts business negotiation with the port and railway through FPMS;

(4) Real-time logistics information: Railway and marine information will be uploaded to FPMS in real time, and the corresponding information will be automatically made available to each participant.

\subsection{Modeling of Container Export Information Flow Based on} Petri Net. Petri net is a structured mathematical language, which can not only describe the process graphically but also convert the graphics into mathematical calculations to evaluate the behavior of the system. The object-oriented traffic system simulation model should be constructed, and the object-oriented idea is combined with Petri net to realize the high reusability and operability of the model, and reduce the scale of the model, which is suitable for all activities, including logistics system. A formal presentation Petri Net is following [25]:

$$
\begin{gathered}
P N=\left(P, T, F, W, M_{0}\right), \\
F \subseteq(P \times T) \cup(T \times P),
\end{gathered}
$$

$P=\left\{p_{1}, p_{2}, \ldots, p_{n}\right\}$ is a finite set of places (Place), which represents the set of nodes and departments where transportation tasks start, end, or information flow, $n$ is the number of finite places.

$T=\left\{t_{1}, t_{2}, \ldots, t_{m}\right\}$ is a finite set of transitions, that is, the set of the execution of transportation tasks or the process of information transmission, and $m$ is the number of finite transitions.

$P$ and $T$ satisfy condition $P \cap T=\varnothing$ and $P \cup T \neq \varnothing$.

$W: F \longrightarrow\{1,2,3, \ldots\}$ is the weight function of the directed arc.

$M_{0}: P \longrightarrow\{0,1,2,3, \ldots\}$ is the initial mark.

Through the Petri Net model, we use OOPN to simulate the flow of container export information. According to the model composition of OOPN, the system composition object and structure are determined by business analysis, and the information flow of container export is modeled according to the following steps:

(1) Divide the composition of information flow system of FPMS into four categories of objects.

(2) Determine the behavior of the class object itself and its relationship with other objects.
(3) Construct the internal behaviors of four types of objects with simple Petri nets.

(4) Based on (3), an object message queue is built and an input/output gate is used to represent the external interface of the object.

(5) Connect corresponding transitions in internal Petri nets of various objects with message teams.

At the same time, to simplify the modeling process, the following assumptions were made for the FPMS process system before model construction:

(1) Railway freight station can provide uniform service within a period of time.

(2) All transport-related departments and personnel related to freight can keep in close contact under normal circumstances.

(3) The relevant personnel of all participants can only handle one business at a time.

(4) The resource consumption of the processing process is constant, regardless of human and external factors.

(5) The event processing results are satisfactory and can be used for the next step.

(6) Each transshipment node has sufficient capacity to deal with transshipment procedures.

An OOPN-based container export FPMS information flow system model can be constructed in the Petri net environment according to the above modeling process and premise assumptions, and taking into account the functional connection between elements. As shown in Figure 7, the related symbolic meanings are shown in Table 5:

\subsection{Detection of FPMS Container Export Information Flow Model Based on Petri Net}

4.6.1. Model Reliability Analysis. At present, the most commonly used OOPN model reliability detection method is system deadlock detection. The so-called deadlock refers to a blocking phenomenon caused by competition for resources or due to communication with each other during the execution of two or more processes. If there is no external force, they will not be able to continue to advance. At this time, it is called the system is in a deadlock state or the system has a deadlock. These processes that are always waiting for each other are called deadlock processes [26]. The deadlock here is a dynamic deadlock, which reflects the dynamic characteristics of the Petri net. It can be checked whether there is a deadlock by detecting the reachable centralized deadlock flag of the Petri net. If the deadlock flag is detected in the reachable set, it will exist. Deadlock, otherwise it does not exist [27]. A reachability tree is an effective tool for checking the deadlock identification of Petri nets. It can cover all reachable sets of Petri nets and all deadlocks at the same time. The deadlock detection process of the reachable tree of the object-oriented Petri net can be divided into the following steps: 


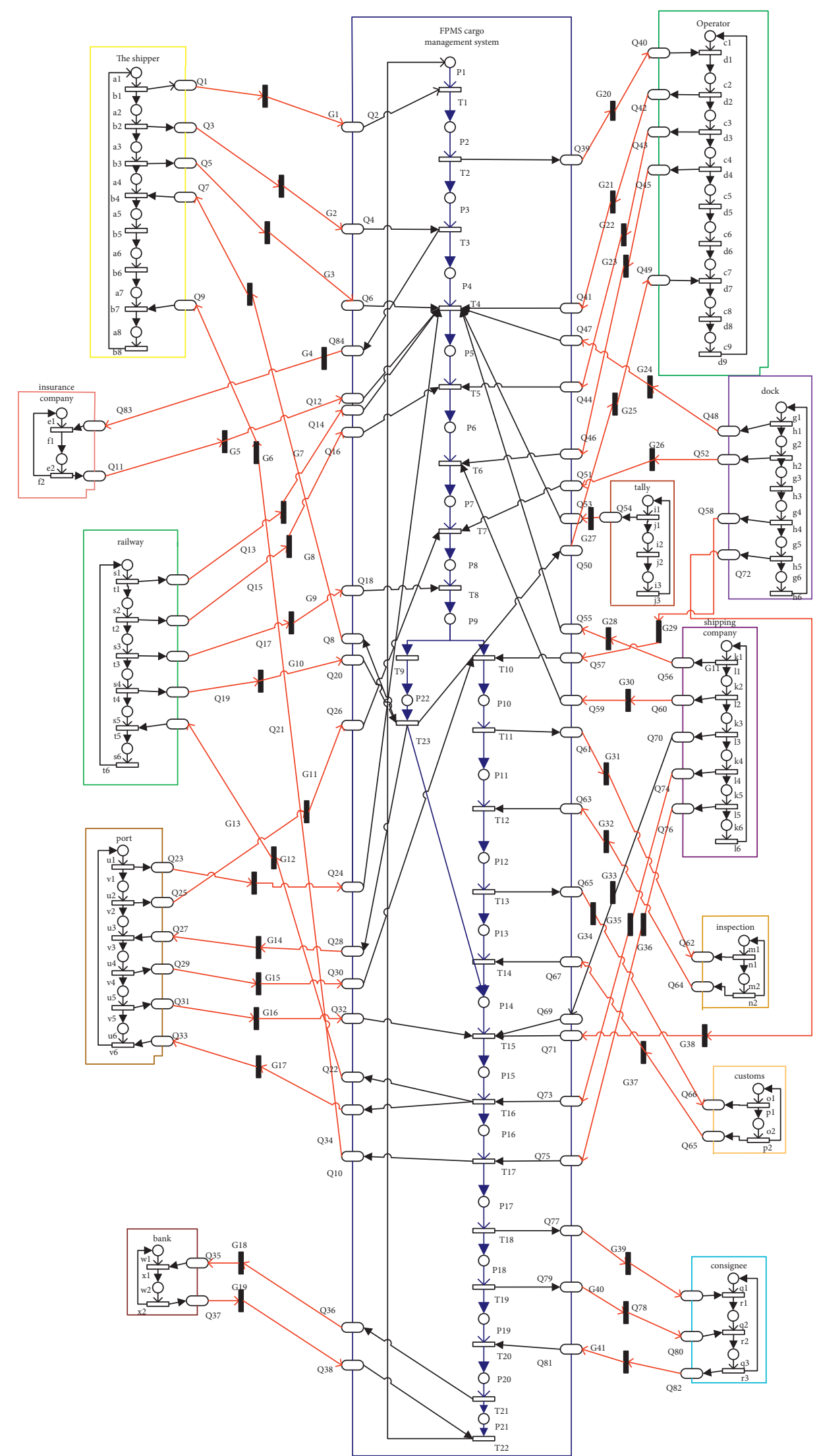

FIGURE 7: FPMS container export information flow model based on OOPN. 
TABLE 5: FPMS OOPN model symbol meaning of container export information flow.

\begin{tabular}{|c|c|}
\hline Symbol & Meaning \\
\hline P1 & Collection of order requirements \\
\hline P2 & The order set \\
\hline P3 & Fill in the request of the whole journey including the waybill \\
\hline $\mathrm{P} 4$ & Transportation scheme design \\
\hline P5 & Request for car reservation and suitcase \\
\hline P6 & Booking request \\
\hline P7 & Unloading request \\
\hline P8 & Packing request \\
\hline P9 & Railway transportation and transfer request \\
\hline $\mathrm{P} 10$ & Preparation for inspection \\
\hline P11 & Inspecting \\
\hline $\mathrm{P} 12$ & Customs preparation \\
\hline $\mathrm{P} 13$ & Customs declaration \\
\hline $\mathrm{P} 14$ & Export preparation request \\
\hline P15 & Shipment departure request \\
\hline $\mathrm{P} 16$ & Maritime transport preparation \\
\hline $\mathrm{P} 17$ & Notification of delivery preparation \\
\hline $\mathrm{P} 18$ & Issuing bill of lading preparation \\
\hline P19 & Cargo delivery notice \\
\hline P20 & Payment request preparation \\
\hline $\mathrm{P} 21$ & Paying \\
\hline $\mathrm{P} 22$ & Railway transportation treatment \\
\hline a1 & Transportation demand \\
\hline a2 & Waiting for the whole waybill \\
\hline a3 & Waiting for an agreement \\
\hline $\mathrm{a} 4$ & Waiting for transportation preparation \\
\hline a5 & Customs preparation \\
\hline a6 & Preparation for inspection \\
\hline a7 & Sea transport preparation \\
\hline a8 & Cargo delivery notice \\
\hline $\mathrm{c} 1$ & Waiting for the shipper to choose \\
\hline$c 2$ & Determining the carrier relationship \\
\hline c3 & Preparation before transportation \\
\hline $\mathrm{c} 4$ & Booking, unloading preparation \\
\hline c5 & Customs declaration preparation \\
\hline c6 & Shipping application \\
\hline c7 & Railway transportation preparation \\
\hline$c 8$ & Sea transport preparation \\
\hline c9 & Cargo delivery notice \\
\hline e1 & Waiting for insurance \\
\hline e2 & Signed insurance negotiation \\
\hline g1 & Waiting for the contract to be signed \\
\hline g2 & Receipt of unloading request \\
\hline g3 & Unloading arrangement in progress \\
\hline g4 & Shipping request \\
\hline g5 & Export preparation \\
\hline g6 & Shipping preparation \\
\hline i1 & Waiting for a contract \\
\hline i2 & Tally preparation \\
\hline $\mathrm{i} 3$ & Shipping advice \\
\hline $\mathrm{k} 1$ & Waiting for a contract \\
\hline k2 & Booking application \\
\hline k3 & Export preparation application \\
\hline $\mathrm{k} 4$ & Shipping advice \\
\hline $\mathrm{k} 5$ & Sea transportation notice \\
\hline k6 & Delivery notice \\
\hline $\mathrm{m} 1$ & Waiting for cargo inspection \\
\hline $\mathrm{m} 2$ & In the inspection \\
\hline o1 & Waiting for goods declaration \\
\hline 02 & Customs declaration \\
\hline
\end{tabular}


TABle 5: Continued.

\begin{tabular}{|c|c|}
\hline Symbol & Meaning \\
\hline $\mathrm{q} 1$ & Waiting for delivery notice \\
\hline $\mathrm{q} 2$ & Waiting for bill of lading \\
\hline q3 & Delivery of goods \\
\hline s1 & Waiting for a contract \\
\hline s2 & Booking request \\
\hline s3 & Packing request \\
\hline s4 & Preparation before rail transportation \\
\hline s5 & Shipping advice \\
\hline s6 & Cargo delivery notice \\
\hline $\mathrm{u} 1$ & Waiting for a contract \\
\hline $\mathrm{u} 2$ & Unloading application \\
\hline $\mathrm{u} 3$ & Railway transportation notice \\
\hline $\mathrm{u} 4$ & Transfer formalities \\
\hline u5 & Export preparation \\
\hline u5 & Shipment departure preparation \\
\hline w1 & Waiting for payment \\
\hline w2 & Payment preparation \\
\hline $\mathrm{T} 1$ & Receive shipping request \\
\hline $\mathrm{T} 2$ & Agent selection \\
\hline T3 & Completed \\
\hline $\mathrm{T} 4$ & Sign contracts, insurance \\
\hline $\mathrm{T} 5$ & The car is ordered and the suitcase is completed \\
\hline T6 & Booking completed \\
\hline $\mathrm{T} 7$ & Unloading plan in progress \\
\hline $\mathrm{T} 8$ & Packing finished \\
\hline T9 & Railway transportation request \\
\hline $\mathrm{T} 10$ & The transfer procedure has been completed \\
\hline $\mathrm{T} 11$ & Inspection request \\
\hline $\mathrm{T} 12$ & Pass the inspection \\
\hline $\mathrm{T} 13$ & Customs request \\
\hline $\mathrm{T} 14$ & Customs clearance \\
\hline $\mathrm{T} 15$ & Export ready \\
\hline $\mathrm{T} 16$ & Shipment departure \\
\hline $\mathrm{T} 17$ & In transit by sea \\
\hline $\mathrm{T} 18$ & Notice delivery \\
\hline $\mathrm{T} 19$ & Issue a bill of lading \\
\hline $\mathrm{T} 20$ & Delivery of goods \\
\hline $\mathrm{T} 21$ & Paid \\
\hline $\mathrm{T} 22$ & Payment completed \\
\hline $\mathrm{T} 23$ & In transit by railway \\
\hline b1 & Shipping request \\
\hline b2 & Completed the entire waybill \\
\hline b3 & The agreement was signed \\
\hline $\mathrm{b} 4$ & Railway transportation \\
\hline b5 & Customs clearance \\
\hline b6 & Pass the inspection \\
\hline b7 & In transit by sea \\
\hline b8 & Delivery of goods \\
\hline $\mathrm{d} 1$ & Selected \\
\hline $\mathrm{d} 2$ & Signing a contract, insurance \\
\hline d3 & Booking and picking up \\
\hline $\mathrm{d} 4$ & Booking and unloading plan is completed \\
\hline d5 & Customs declaration \\
\hline d6 & Out of the box \\
\hline d7 & In transit by railway \\
\hline $\mathrm{d} 8$ & In transit by road \\
\hline d9 & Delivery of goods completed \\
\hline f1 & Signing an insurance claim \\
\hline $\mathrm{f} 2$ & Signed insurance completed \\
\hline h1 & Completion of contract \\
\hline
\end{tabular}


TABLE 5: Continued.

\begin{tabular}{|c|c|}
\hline Symbol & Meaning \\
\hline h2 & Preparation for unloading plan \\
\hline h3 & Unloading list completed \\
\hline h4 & Out of the box \\
\hline h5 & Export configuration list \\
\hline h6 & Shipment, departure \\
\hline j1 & The contract is signed \\
\hline $\mathrm{j} 2$ & Check the goods \\
\hline j3 & Shipment departure \\
\hline 11 & The contract is signed \\
\hline 12 & Booking completed \\
\hline 13 & Export preparation \\
\hline 14 & Shipment departure \\
\hline 15 & Sea transport \\
\hline 16 & Delivery of goods \\
\hline $\mathrm{n} 1$ & Application for inspection \\
\hline $\mathrm{n} 2$ & Pass the inspection \\
\hline p1 & Customs application \\
\hline $\mathrm{p} 2$ & Customs clearance \\
\hline $\mathrm{R} 1$ & Pick up notice \\
\hline $\mathrm{r} 2$ & Receive bill of lading \\
\hline $\mathrm{r} 3$ & Receiving finished \\
\hline $\mathrm{t} 1$ & The contract is signed \\
\hline $\mathrm{t} 2$ & After ordering \\
\hline $\mathrm{t} 3$ & Packing completed \\
\hline $\mathrm{t} 4$ & Rail transport \\
\hline t5 & Shipment departure \\
\hline t6 & Delivery of goods \\
\hline $\mathrm{v} 1$ & The contract is signed \\
\hline v2 & Unloading completed \\
\hline v3 & Railway transportation \\
\hline $\mathrm{v} 4$ & The transfer procedure has been completed \\
\hline v5 & Export ready \\
\hline v6 & Shipment departure \\
\hline $\mathrm{x} 1$ & Payment request \\
\hline $\mathrm{x} 2$ & Payment completed \\
\hline
\end{tabular}

(1) According to the internal structure of each object, extract its input/output gates and the order of occurrence, and construct an interface equivalent net (IE network).

(2) Combine the different object IE networks in (1) to form the system IE network.

(3) By performing a reachable tree analysis on the established IE network, it is detected whether there is a deadlock. If it exists, the established model needs to be improved to eliminate the deadlock; otherwise, the system is reliable.

Through the analysis of reachable trees and Internet Explorer, it is obvious that there is no deadlock in the freight process management system of FPMS. Similarly, it can be concluded that there is no deadlock in other objects, such as railways, ports, shippers, and through transport operators. Therefore, there is no deadlock in the entire OOPN model.

4.6.2. Bounded Analysis. Boundedness is an indicator to measure whether the resource demand of the system is limited in operation, and it represents the maximum number of tokens that can be obtained during the operation of the system where the library is located. In the running process of the Petri net, there is an integer $K$ that makes the number of tokens in the library in any reachable identifiers of the initial identifiers not exceed $K$, so that the Petri net is $k$-bounded.

4.6.3. Performance Comparison. (1) Process analysis: the main flow before and after reconstruction is simulated and compared according to the traditional freight transport flow mentioned in this paper. Before the reconstruction, the freight forwarder's land transportation order was received by the railway, and the freight bill was directly delivered to different ports. All the information is submitted to FPMS, and the order information is sent synchronously to all the intermodal participants after the reconstruction. In the single-node physical host environment, ExSpect software was used to simulate and analyze the Petri net model before and after reconstruction. The simulation diagram is shown in Figures 8 and 9. The main process time was shown in Tables 6 and 7, and the experimental results were shown in Tables 8 and 9 .

The simulation results in Table 8 show that (1) the process cycle is long, with an average cycle of about 5528 


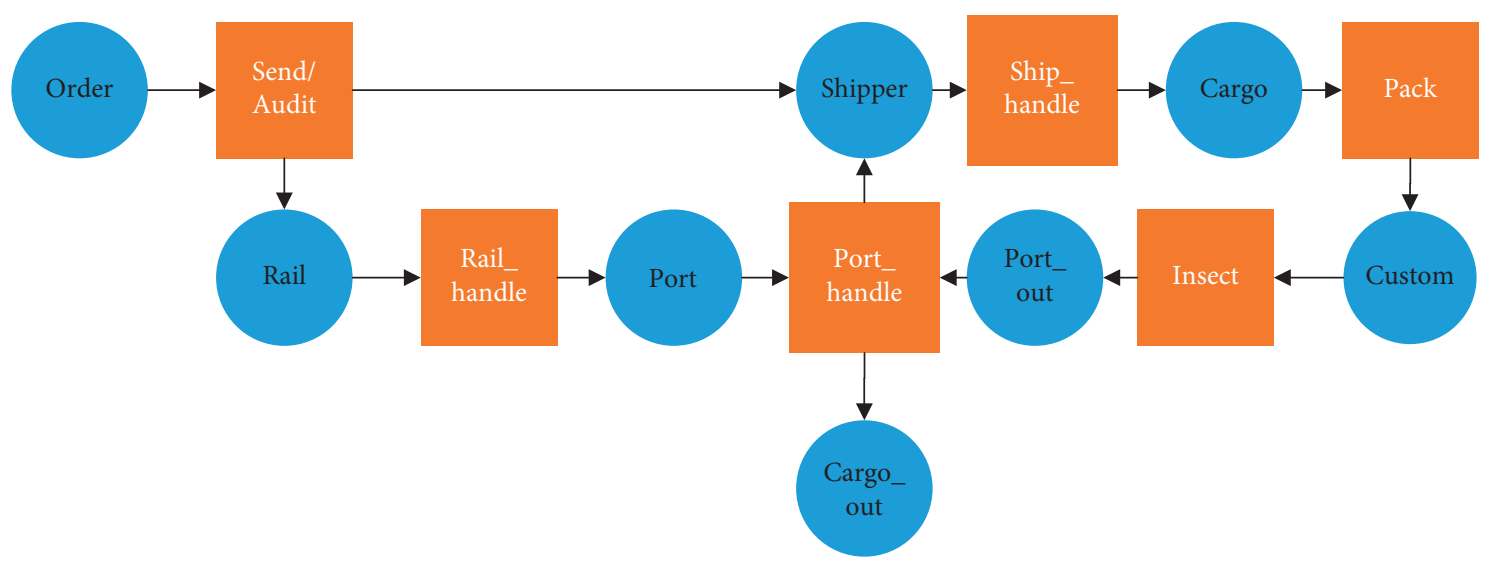

FIGURE 8: Process simulation screenshot before reconstruction.

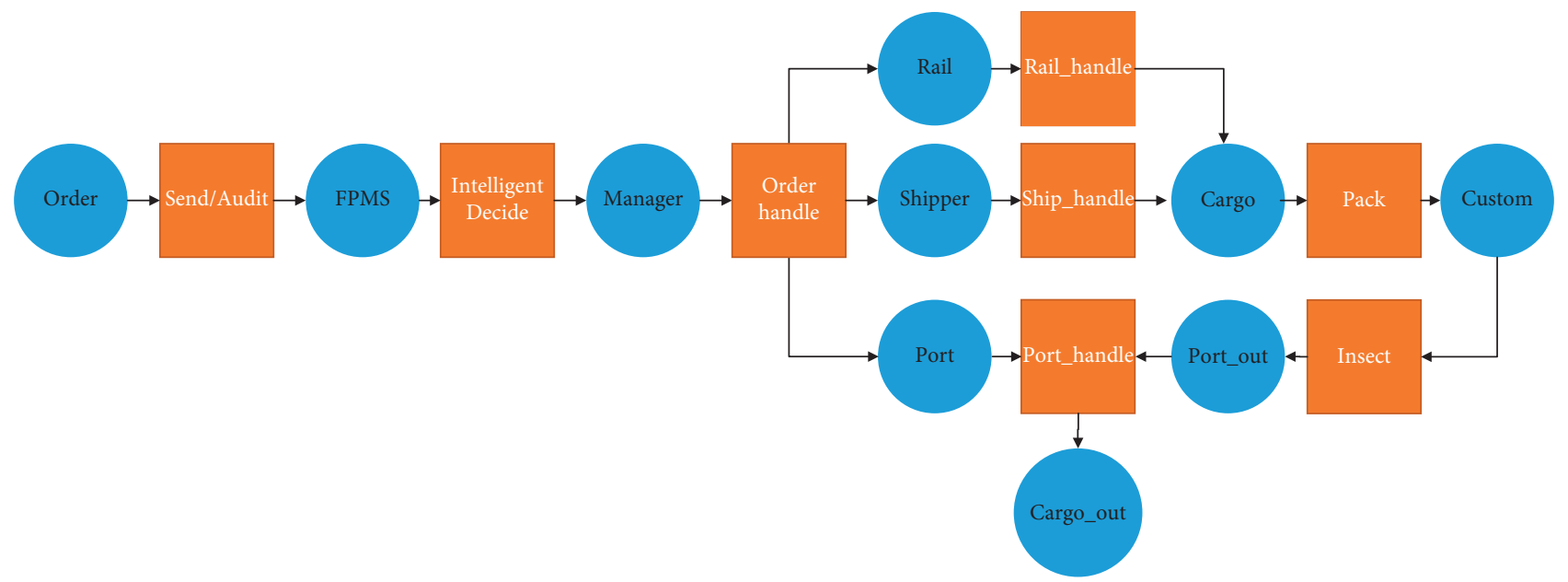

FIGURE 9: Process simulation screenshot after reconstruction.

TABle 6: Time consumption ( $\mathrm{min}$ ) of main business links of the process before reconstruction.

\begin{tabular}{lcc}
\hline Business & Process & Time \\
\hline Send/audit & Order delivery and review & $1440-2880$ \\
Rail_handle & Railway handling & $2880-5760$ \\
port_handle & Suitcase & $2880-5760$ \\
Ship_handle & Loading & $2880-5760$ \\
Pack & Tally & $1440-2880$ \\
Insect & Customs inspection process & $1440-2880$ \\
\hline
\end{tabular}

TABLE 7: Time consumption (min) of main business links of the process after reconstruction.

\begin{tabular}{lcc}
\hline Business & Process & Time \\
\hline intelligentDecide & Order collection and intelligent matching, order submission to the freight process management system, the & $2-3$ \\
Order_handle & system network for real-time transmission of messages & $2-3$ \\
Rail_handle & The cloud platform processes/distributes orders & $2880-5760$ \\
Port_handle & Railway handling & $2880-5760$ \\
Ship_handle & Suitcase & $2880-5760$ \\
Pack & Loading & $1440-2880$ \\
Insect & Tally & $1440-2880$ \\
\hline
\end{tabular}


TABLE 8: Simulation results of freight flow before reconstruction.

\begin{tabular}{lccc}
\hline Group number & Number of process samples & Average process cycle time $(\mathrm{min})$ & The variance \\
\hline 1 & 83 & 5631.1 & 2310.1 \\
2 & 127 & 5579.8 & 1924.3 \\
3 & 130 & 5713.4 & 1894.6 \\
4 & 122 & 5418.3 & 1806.8 \\
5 & 119 & 5297.4 & 1993.5 \\
\hline
\end{tabular}

TABLE 9: Simulation results of freight flow after reconstruction.

\begin{tabular}{lccc}
\hline Group number & Number of process samples & Average process cycle time (min) & The variance \\
\hline 1 & 75 & 3981.7 & 234.4 \\
2 & 140 & 3511.8 & 199.8 \\
3 & 94 & 3420.4 & 213.3 \\
4 & 133 & 3313.1 & 220.4 \\
5 & 129 & 3403.6 & 210.7 \\
\hline
\end{tabular}

minutes, and (2) large variance value, large dispersion degree, process instability, and uncertainty.

The analysis of the process shows that (1) the process has a long cycle because the serial structure is adopted, and the information transfer process needs to consume time. Meanwhile, the process is processed in advance according to experience. (2) The process has a large dispersion degree, which indicates that the process is greatly influenced by uncertain factors, and the system stability is weak.

The simulation results in Table 9 show that (1) the cycle time of this process is shorter than that of the original process, with an average cycle time of about 3526 minutes. Compared with the original process after optimization, the average cycle time of the freight flow is shortened by $36.21 \%$. (2) The variance value is smaller, the system dispersion degree is reduced, and the process stability is improved.

According to the analysis of the process, the reconstructed freight flow management system simplifies the information interaction and processing process in the freight process, reduces the repeated input of data, and thus shortens the time of information handover. In addition, the business coherence and parallelism can be improved because of the real-time order information, and the freight transport efficiency can be improved significantly. After the electronic standardization of the system, the uncertainty is reduced, the process stability is greatly improved, and the process synchronization and efficiency of operation are realized. The system load is relatively balanced by adopting the Big Data platform processing mode in the cloud environment, while the data processing capacity is greatly improved, the resource utilization rate is higher, and the execution rate is also higher.

\section{Conclusion}

Based on the hindrance of the overall development of railway-river business at present, combined with the current situation of the decentralized layout of the intermodal transportation information system, this paper puts forward the idea of constructing the information layout of the cloud platform for intermodal transportation, and takes Chinese container as an example to realize the optimization of the freight business process of the joint transport of railway-river and freight. The application of Big Data, cloud computing and other technologies provides a large amount of real-time sharing, connectivity and interaction information for intermodal transportation operators, railways, ports, and shipping companies, saves the time cost of business development, and improves the business efficiency and security; for government agencies, such as customs clearance and inspections, the unified resource management mode provides the possibility of real-time query of all orders to ensure the quality of each cargo. There are records to track, which improves the administrative efficiency; for the container truck distribution company and insurance bank, it provides real-time interactive application information, which is conducive to timely adjust the service mode and better adapt to the business needs. In a word, it is very necessary to adopt the "big centralized" information management mode under the Big Data platform to realize the business process reconstruction of intermodal transportation to meet the business development needs of current intermodal transportation informatization.

Due to the large number of participating institutions of the intermodal information platform, the large business complexity, and the large number of legacy systems, there is no precedent for the introduction of cloud computing technology into intermodal information construction and the potential knowledge mining of intermodal Big Data. There is still a broad development space in the construction of the intermodal cloud platform, and long-term practice and exploration are still needed. This article has the following points to focus on in the follow-up.

5.1. Standardization of Cloud Platform for Rail Water Transport. Due to the imperfect information standards of rail water intermodal transportation in China, most of the current application architectures cannot adapt to the cloud environment. Although the intermodal transportation cloud platform is environmentally compatible with the legacy applications, a lot of reconstruction work 
is still needed for the current information. Due to the different business processes of different ports and the different information exchange standards, it is difficult to implement the application and information integration process on the intermodal cloud platform, which also requires a lot of human and material resources. Although the simple migration can realize the unified management of the application, it cannot effectively use the virtual resources to optimize the cloud service mode.

\subsection{Information Isolation between Intermodal Applications.} A large number of intermodal applications reside in the cloud and share the virtual computing resources and storage resources of the cloud in the intermodal cloud platform environment. How to isolate the internal and external service data while ensuring the information sharing requirements and protect the privacy of the business application information of the intermodal departments involved are also issues that need to be considered. Although virtualization technology provides a data isolation mechanism, more in-depth research is needed on data partitioning, protection, and utilization.

5.3. Data Fusion in the Internet-of-Things Environment. With the advent of the Internet-of-Things era, the crossborder integration of the interoperability industry and the Internet of Things is the only way to improve business and management efficiency, realize intelligent management, and maintain advancement. In the Internet-of-Things environment, massive sensor data will enter the intermodal cloud platform. How to use the powerful data processing capabilities of cloud computing to realize the analysis and processing of massive real-time sensor information will also be a severe challenge.

\section{Data Availability}

The data used to support the findings of this study are included within the article.

\section{Conflicts of Interest}

The authors declare that they have no conflicts of interest.

\section{Authors' Contributions}

Furong Jia and Lin Sun contributed to the work equally and should be regarded as co-first authors.

\section{Acknowledgments}

This work was supported in part by the National Key R\&D Program of China (grant nos. 2017YFB1200702 and 2016YFC0802208), National Natural Science Foundation of China (project no. 61703351), Sichuan Science and Technology Program (project nos. 2018RZ0078 and 2019JDR0211), Science and Technology Plan of China Railway Corporation (project no. P2018T001), Chengdu Soft Science Research Project (grant nos. 2017-RK00-00028-ZF and
2017-RK00-00378-ZF), and the Fundamental Research Funds for the Central Universities (grant nos. 2682017CX022 and 2682017CX018. This research was also funded by Sichuan Agricultural University education reform projects X2013039 and X2014025, "Agricultural Information Engineering," Sichuan key laboratory of higher education.

\section{References}

[1] Y. Tingyu, P. Xiaoqian, C. Dingjun et al., "Research on transregion integrated traffic emergency dispatching technology based on multi-agent," Journal of Intelligent and Fuzzy Systems, vol. 38, pp. 1-12, 2020.

[2] S. Liu, C. Yin, D. Chen et al., "Cascading failure in multiple critical infrastructure interdependent networks of syncretic railway system," IEEE Transactions on Intelligent Transportation Systems, 2021.

[3] D. Chen, S. Ni, C. A. Xu, and X. Jiang, "Optimizing the draft passenger train timetable based on node importance in a railway network," Transportation Letters, vol. 11, no. 1, pp. 20-32, 2019.

[4] K. Che, X. Wang, Possible sustainability of intermodal transportation in Africa," Open Journal of Applied Sciences, vol. 9, no. 4, pp. 139-158, 2019.

[5] Z. Li, "Design and implementation of credit information system based on data centralization mode," M. S. thesis, Department of Computer Applications Technology, Hunan University, Changsha, China, 2010.

[6] P. He and W. Li, "Modeling and analysis of logistics distribution process based on Stochastic Petri net," Journal of Wuhan University of Technology, vol. 32, no. 3, pp. 434-436, 2010.

[7] F. Cao, "New ideas on regional economic development and industrial transformation under "jinjiang experience" A new logistics model based on the establishment of three-port linkage," Advances in Economics, Business and Management Research, vol. 71, pp. 86-94, 2018.

[8] X. Chen, "An empirical analysis of competitiveness of yangshan deep-water port: the application of intermodal transportation and automated container terminal," in Proceedings of the 2019 2nd International Workshop on Advances in Social Sciences (IWASS 2019), pp. 111-122, London, UK, November 2019.

[9] T. Chen, Q. Huang, and S. Ni, "Research on the architecture scheme of the information platform of railway-river combined transport based on cloud computing," Logistics technology, vol. 23, pp. 404-407, 2014.

[10] Meng, "The research based on private cloud computing information interaction model," in Proceedings of the 2015 International Conference on Automation, Mechanical Control and Computational Engineering (AMCCE 2015), Ji'nan, China, April 2015.

[11] S. Cao, S. Chu, and B. Zhang, "Practice and research on construction management of engineering project for newgeneration large-scale high-speed railway passenger station," in Proceedings of the 8th International Symposium on Project Management, China (ISPM2020), pp. 378-396, Aussino Academic Publishing House, Beijing, China, July 2020.

[12] H. W. Wang, C. H. Chen, D. Y. Cheng et al., "A real-time pothole detection approach for intelligent transportation system," Mathematical Problems in Engineering, vol. 2015, Article ID 869627, 7 pages, 2015. 
[13] W. Jansen and T. S. P. Grance, Guidelines on Security and Privacy in Public Cloud Computing, National Institute of Standards \& Technology, Gaithersburg, MA, USA, 2011.

[14] C. L. Iacovou, I. Benbasat, and A. S. Dexter, "Electronic data Interchange and small organizations: adoption and impact of technology," MIS Quarterly, vol. 19, no. 4, pp. 465-485, 1995.

[15] J. Mantas, A. Hasman, and H. Arie, Electronic Data Interchange, IOS Press, Amsterdam, Netherlands, 2002.

[16] P. García-Sánchez, J. González, P. A. Castillo, M. G. Arenas, and J. J. Merelo-Guervós, "Service oriented evolutionary algorithms," Soft Computing, vol. 17, no. 6, pp. 1059-1075, 2013.

[17] R. Singh Bhadoria, N. S. Chaudhari, and G. Singh Tomar, "The Performance Metric for Enterprise Service Bus (ESB) in SOA system: theoretical underpinnings and empirical illustrations for information processing," Information Systems, vol. 65, 2017.

[18] B. Benatallah and H. R. Motahari Nezhad, "Service oriented architecture: overview and directions," in Advances in Software Engineering, E. Börger and A. Cisternino, Eds., vol. 5316, 2008.

[19] Sonic Software Corporation, Sonic ESB: An Architecture and Lifecycle Definition, Sonic White Paper, Novato, CA, USA, 2005.

[20] S. Hudson, "The Enterprise service bus: disruptive technology for software infrastructure solutions," IDC Insight, vol. 1, 2003.

[21] E. Kozan, "Optimising container transfers at multimodal terminals," Mathematical and Computer Modelling, vol. 31, no. 10-12, pp. 235-243, 2000.

[22] R. Rajkovic, N. Zrnic, S. Kirin, and B. Dragovic, "A review of multi-objective optimization of container flow using sea and land legs together," FME Transaction, vol. 44, no. 2, pp. 204-211, 2016.

[23] C. WANG, D. César, and W. WANG, "Port integration in China: temporal pathways, spatial patterns and dynamics," Chinese Geographical Science, vol. 25, no. 5, pp. 612-628, 2015.

[24] J.-S. Pan, N. Liu, S.-C. Chu, and T. Lai, "An efficient surrogateassisted hybrid optimization algorithm for expensive optimization problems," Information Sciences, vol. 561, pp. 304325, 2021.

[25] T. Murata, "Petri nets: properties, analysis and applications," Proceedings of the IEEE, vol. 77, no. 4, pp. 541-580, 1989.

[26] W. Nie, Business Process Optimization of Railway Logistics Center Based on Petri Net, Southwest Jiaotong University, Chengdu, China, 2012.

[27] L. Huang, Research on Multithreaded Deadlock Detection Based on Petri Nets, University of Science and Technology of China, Hefei, China, 2015. 